Www.jmscr.igmpublication.org

Impact Factor (SJIF): 6.379

Index Copernicus Value: 79.54

ISSN (e)-2347-176x ISSN (p) 2455-0450

crossrefDOI: https://dx.doi.org/10.18535/jmscr/v6i10.117

Journal Of Medical Science And Clinical Research

\title{
NAFLD and Thyroid Status: A Cross Sectional Study at a Tertiary Care Unit
}

\author{
Dr Narendra Kumar ${ }^{1}$, Dr Vibha Sushilendu ${ }^{2}$, Dr Hussain Ahmad ${ }^{3}$ \\ ${ }^{1}$ Senior Resident, Dept of General Medicine, NMCH, Patna \\ ${ }^{2}$ Senior Resident, Dept of Biochemistry, IGIMS, Patna \\ ${ }^{3}$ Prof., Dept of General Medicine, NMCH, Patna, India
}

\begin{abstract}
NAFLD is a chronic liver disease with a broad clinical spectrum. There has been a significant increase in the frequency of non-alcoholic fatty liver disease (NAFLD), throughout the past periods. Thyroid hormones control all the metabolic pathways, acting on carbohydrates, protein and lipid metabolism. According to some studies, the prevalence of hypothyroidism is from 15.2 to $36.3 \%$ among patients with NAFLD, thus indicating that hypothyroidism is a common concomitant disease of NAFLD and may be related to the development of NAFLD.100 NAFLD cases and 50 age and sex matched healthy controls were enrolled for this study. Mean TSH level in NAFLD cases was $3.6 \pm 1.5 \mu \mathrm{IU} / \mathrm{ml}$ while in control group, it was $2.1 \pm$ $0.95 \mu \mathrm{IU} / \mathrm{ml}$. Hypothyroidism is a risk factor for NAFLD. As hypothyroidism is a modifiable risk factor which can be treated with thyroid replacement therapy, thyroid hormone profiles must be tested as a part of initial clinical assessment in patients with NAFLD.

Keywords: NAFLD, hypothyroidism, euthyroidism.
\end{abstract}

\section{Introduction}

NAFLD is a chronic liver disease defined as accumulation of fat in the liver in absence of excess alcohol consumption. Both insulin resistance (IR) and genetic predisposition play a key role in its pathogenesis. Non alcoholic fatty liver disease (NAFLD) represents a broad clinical spectrum which ranges from simple fatty liver to non alcoholic steatohepatitis (NASH), that may progress to liver fibrosis, cirrhosis and hepatocellular carcinoma ${ }^{[1]}$.

There has been a significant increase in the frequency of non-alcoholic fatty liver disease (NAFLD), throughout the past periods. NAFLD has become the prominent reason of liver disease worldwide, with a global prevalence of $25 \%$. This can be moderately attributed to the rising prevalence of obesity ${ }^{[2,3]}$. An increasing number of diseases, such as cardiovascular disease, type 2 diabetes, chronic kidney disease, and cancer, have been reported to be linked to NAFLD. The prevention and treatment of NAFLD have become the focus of medical research in recent years, and identification of the risk factors for NAFLD is critical to develop effective preventive interventions against NAFLD ${ }^{[4-6]}$.

Thyroid hormones control all the metabolic pathways, acting on carbohydrates, protein and lipid metabolism. Low levels of thyroid hormone are related with hypometabolism which are 
categorized by weight gain, decreased resting energy expenditure, reduced lipolysis, increased cholesterol levels, and reduced gluconeogenesis. Thyroid hormones similarly play a role in hepatic lipid metabolism and hepatic insulin resistance ${ }^{[7,8]}$. Hypothyroidism comprises of both subclinical hypothyroidism and overt hypothyroidism. Previous studies propose that hypothyroidism might play a crucial role in the pathogenesis of NAFLD. According to some studies, the prevalence of hypothyroidism is from $15.2 \%$ to $36.3 \%$ among patients with NAFLD, thus indicating that hypothyroidism is a common concomitant disease of NAFLD and may be related to the development of NAFLD ${ }^{[9]}$.

\section{Material and Methods}

This cross-sectional, observational study was done in the department of Medicine, Nalanda Medical College and Hospital, Patna. For cases, 100 USG proven NAFLD patients were selected between age group 18-75 years. Patients with viral hepatitis or past history of alcohol intake were excluded from the study.50 age and sex matched healthy volunteers were taken as control.

$2 \mathrm{ml}$ sample was collected in plain vial, from anticubital vein after an overnight fast. Serum was analysed for fT3, fT4, TSH, lipid profile and liver enzymes(AST/ALT).

All the statistical analysis were done using SPSS software. Datas are expressed as mean \pm 1 SD. $p$ value $<0.05$ is considered statistically significant.

\section{Results}

In the NAFLD case group, there were 67 males and 33 females. Healthy control group consisted of 18 females and 32 males .The mean age of cases was $48 \pm 15.3$ years while the mean age of control was $45 \pm 12.4$ years. $36 \%$ patients in the case group were found to be hypothyroid (both subclinical and overt hypothyroidism) but only $12 \%$ of the control group were diagnosed with hypothyroidism hypothyroidism).

Subjects with TSH level $>5 \mu \mathrm{IU} / \mathrm{ml}$ but normal level of fT3 $(2.50-3.90 \mathrm{pg} / \mathrm{ml})$ and fT4(0.61$1.21 \mathrm{ng} / \mathrm{ml}$ ) were considered under subclinical hypothyroidism. Mean TSH level in NAFLD cases was $3.6 \pm 1.5 \mu \mathrm{IU} / \mathrm{ml}$ while in control group ,it was $2.1 \pm 0.95 \mu \mathrm{IU} / \mathrm{ml}$. The level of fT3 and fT4 in NAFLD cases were $2.72 \pm 0.06 \mathrm{pg} / \mathrm{ml}$ and 0.82 $\pm 0.05 \mathrm{ng} / \mathrm{ml}$ respectively. Among the control,fT3 and fT4 were found to be $3.21 \pm 0.17 \mathrm{pg} / \mathrm{ml}$ and $0.98 \pm 0.14 \mathrm{ng} / \mathrm{ml}$ respectively.

NAFLD patients with hypothyroidism had mean ALT level 100.7 $\pm 39.8 \mathrm{IU} / 1$ and mean AST level of 89.6 \pm 34.3 IU/1. Similarly the mean ALT and AST level in euthyroid NAFLD patients were $78.2 \pm$ $27.6 \mathrm{IU} / 1$ and $75.9 \pm 29.8 \mathrm{IU} / 1$ respectively. Thus the ALT-AST levels in hypothyroid NAFLD patients were significantly raised ( $p$ value $<0.05$ ) than the euthyroid NAFLD patients.

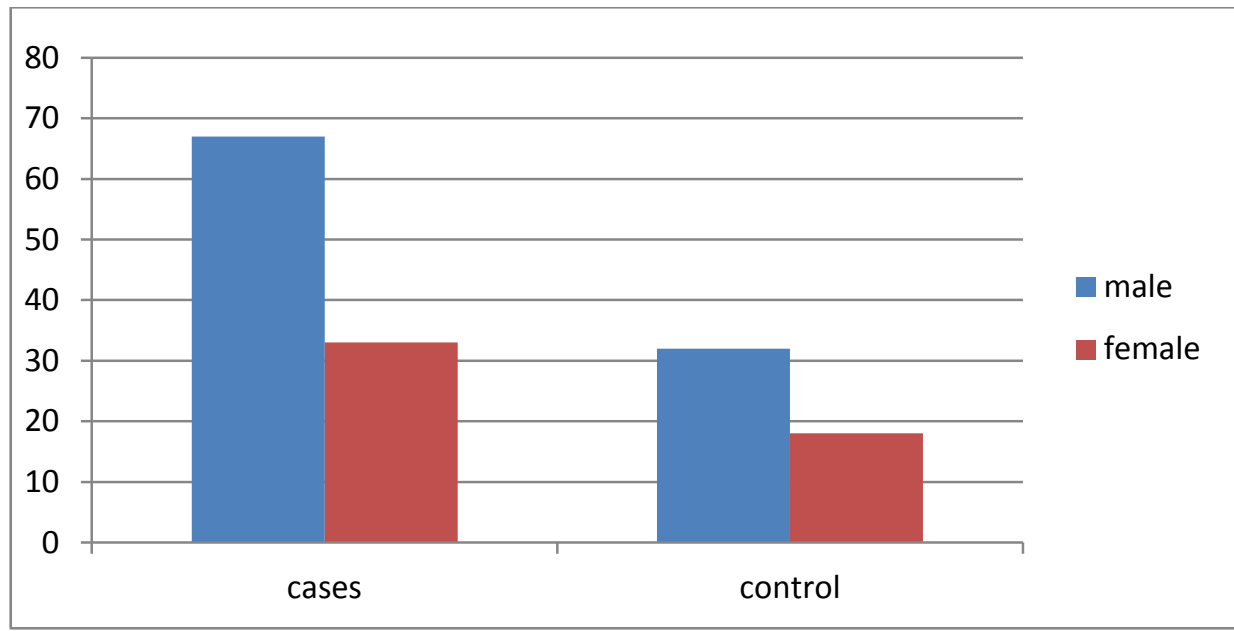

Fig 1: Sex distribution in case and control group 


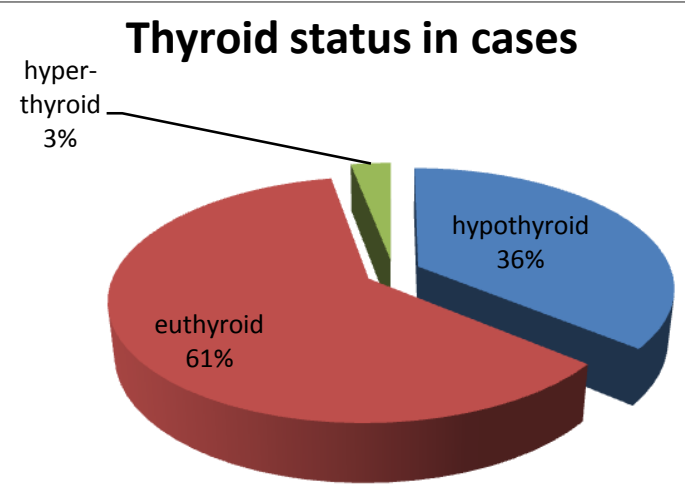

Fig 2: Percentage distribution of different thyroid status in NAFLD cases

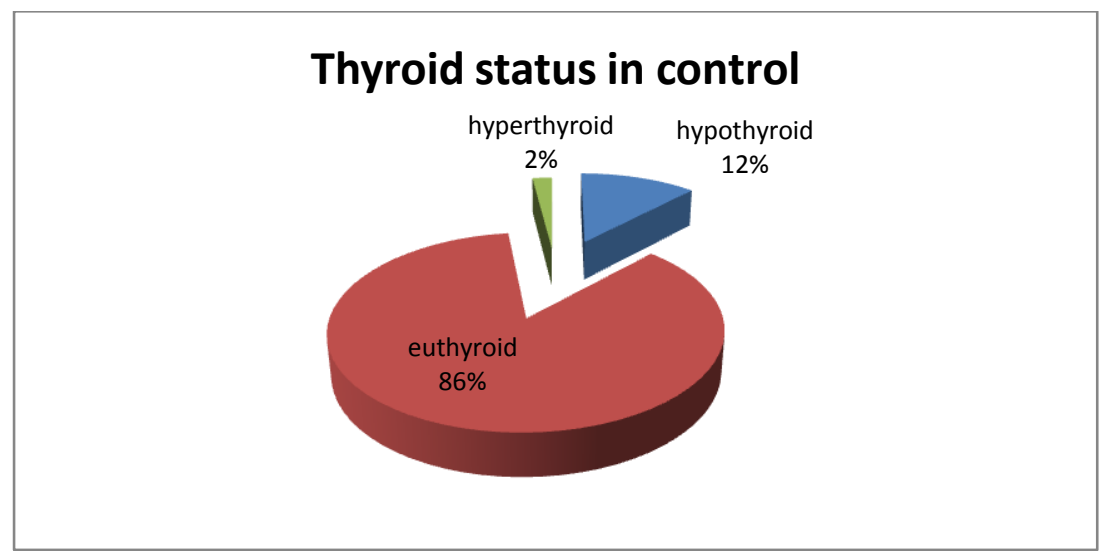

Fig 3: Percentage distribution of different thyroid status in the control group

Table 1: Comparative study of biochemical parameters between cases and control

\begin{tabular}{|l|c|c|c|}
\hline & CASES & CONTROL & p value \\
\hline BMI & $27.6 \pm 4.5$ & $22.8 \pm 3.9$ & $<0.001$ \\
\hline FBS(mg/dl) & $107.6 \pm 25.3$ & $85.2 \pm 21.7$ & 0.03 \\
\hline Total Cholesterol(mg/dl) & $256.8 \pm 47.1$ & $197.6 \pm 41.5$ & $<0.001$ \\
\hline HDL(mg/dl) & $35.6 \pm 7.3$ & $42.5 \pm 8.9$ & $<0.001$ \\
\hline LDL(mg/dl) & $125 \pm 36.7$ & $98.4 \pm 27.6$ & $<0.001$ \\
\hline TG(mg/dl) & $200.9 \pm 86.3$ & $164.7 \pm 61.2$ & $<0.001$ \\
\hline ALT(IU/l) & $82.7 \pm 28.5$ & $22.7 \pm 9.4$ & $<0.001$ \\
\hline AST(IU/l) & $79.6 \pm 24.6$ & $20.8 \pm 7.9$ & $<0.001$ \\
\hline
\end{tabular}

Table 2: Comparative study of Thyroid hormones level between cases and control

\begin{tabular}{|l|c|c|c|}
\hline & CASES & CONTROL & p value \\
\hline fT3 $(\mathrm{pg} / \mathrm{ml})$ & $2.72 \pm 0.06$ & $3.21 \pm 0.17$ & $<0.001$ \\
\hline $\mathrm{fT} 4(\mathrm{ng} / \mathrm{ml})$ & $0.82 \pm 0.05$ & $0.98 \pm 0.14$ & $<0.001$ \\
\hline $\mathrm{TSH}(\mu \mathrm{IU} / \mathrm{l})$ & $3.60 \pm 1.5$ & $2.12 \pm 0.90$ & $<0.001$ \\
\hline
\end{tabular}

Table 3: Comparative study of analytes between hypothyroid and euthyroid group of NAFLD cases

\begin{tabular}{|l|c|c|c|}
\hline & HYPOTHYROID CASES & EUTHYROID CASES & $\mathrm{p}$ value \\
\hline Total Cholesterol(mg/dl) & $274.9 \pm 56.8$ & $248.6 \pm 50.4$ & 0.01 \\
\hline HDL $(\mathrm{mg} / \mathrm{dl})$ & $33.7 \pm 7.1$ & $36.2 \pm 7.4$ & 0.20 \\
\hline LDL $(\mathrm{mg} / \mathrm{dl})$ & $156.7 \pm 27.6$ & $120.5 \pm 21.4$ & $<0.001$ \\
\hline TG(mg/dl) & $243.0 \pm 44.6$ & $196.8 \pm 38.6$ & $<0.001$ \\
\hline AST(IU/l) & $89.7 \pm 34.8$ & $75.8 \pm 25.7$ & 0.02 \\
\hline ALT(IU/l) & $100.6 \pm 39.8$ & $78.5 \pm 27.9$ & 0.01 \\
\hline fT3 $(\mathrm{pg} / \mathrm{ml})$ & $1.81 \pm 0.16$ & $2.76 \pm 0.21$ & $<0.001$ \\
\hline fT4 $(\mathrm{ng} / \mathrm{ml})$ & $0.48 \pm 0.08$ & $0.91 \pm 0.18$ & $<0.001$ \\
\hline TSH $(\mu \mathrm{IU} / \mathrm{l})$ & $7.61 \pm 3.82$ & $3.23 \pm 1.67$ & $<0.001$ \\
\hline
\end{tabular}




\section{Discussion}

In this study, it was found that the lipid profile and BMI of NAFLD cases were significantly raised than the control with a $\mathrm{p}$ value $<0.001$.Even in the NAFLD patients, all the lipid profile parameters except HDL were found to be significantly increased in the hypothyroid group than the euthyroid group. HDL in the hypothyroid NAFLD cases was increased but not significantly ( $p$ value 0.2 ) than the euthyroid NAFLD cases.

Cable et al showed that liver steatosis reduces after treatment of animal models with livertargeted thyroid hormone receptor agonist. Furthermore, hypothyroidism and elevated TSH result in decreased hepatic lipoproteine lipase activity and thus cause elevated serum triglyceride levels ${ }^{[10-12]}$.

Chung et $a l^{[13]}$, in their population based study, evaluated a relatively large numbers of healthy individuals and showed that the prevalence of NAFLD with elevated alanine aminotransferase (ALT) was higher in patient with hypothyroidism. In this study, it was found that hypothyroid NAFLD patients had significantly higher hepatic enzymes (ALT-AST) when compared to euthyroid NAFLD cases.

Thyroid hormones regulate lipid metabolism in the liver via thyroid hormone receptor $\beta$, which decrease cholesterol and triglyceride levels. Lower levels of thyroid hormones in hypothyroidism increase the levels of cholesterol, LDL and triglyceride, but decrease the level of (HDL), and thus can affect lipid metabolism ${ }^{[14-17]}$. Therefore, patients with overt hypothyroidism often have fatty infiltration in the liver and thus have a higher risk for the development of NAFLD. Hypercholesterolemia caused by hypothyroidism also plays an important role in the pathogenesis of NAFLD $^{[18,19]}$.

TSH via TSH receptor signal has a direct impact on hepatic metabolism. TSH can directly increase hepatic gluconeogenesis, repress synthesis of bile acids, and cause hypercholesterolemia by decreasing HMG-CoA reductase phosphorylation. All these factors further leads to the development of NAFLD. Elevated level of oxidative stress markers can be seen in hypothyroidism patients which is one of the mechanisms of NAFLD. Increased oxidative stress in liver tissue among hypothyroidism patients can cause cellular injury by reducing beta-oxidation of fatty acids and increasing peroxidation of lipids ${ }^{[20-24]}$.

In a prospective, population-based study, it was found that compared with euthyroid participants, those with hypothyroidism appeared to have a higher risk for nonalcoholic fatty liver disease (NAFLD). The study demonstrated a negative linear association between free $\mathrm{T} 4$ (thyroxine) levels and incident NAFLD, even among euthyroid subjects, as well as a positive linear association for TSH levels ${ }^{[25]}$.

\section{Conclusion}

Hypothyroidism is a risk factor for NAFLD. As hypothyroidism is a modifiable risk factor which can be treated with thyroid replacement therapy, thyroid hormone profiles must be tested as a part of initial clinical assessment in patients with NAFLD. Further studies and research are required to evaluate whether treatment of hypothyroidism in patients with NAFLD will improve disease progression and outcome.

\section{References}

1. Law K, Brunt EM. Nonalcoholic fatty liver disease. Clin Liver Dis 2010; 14: 591-604 [PMID: 21055684 DOI: 10.1016/ j.cld.2010.07.006]

2. Younossi ZM, Koenig AB, Abdelatif D, Fazel Y, Henry L, Wymer M. Global epidemiology of nonalcoholic fatty liver disease - meta-analytic assessment of prevalence, incidence, and outcomes. Hepatology. 2016;64:73-84.

3. Rinella ME. Nonalcoholic fatty liver disease: a systematic review. JAMA. 2015;313(22):2263-73.

4. Motamed N, Rabiee B, Poustchi H, Dehestani B, Hemasi GR, Khonsari MR, et al. Non-alcoholic fatty liver disease 
(NAFLD) and 10-year risk of cardiovascular diseases. Clin Res Hepatol Gastroenterol (2017) 41(1):31-8. doi:10.1016/j.clinre.2016.07.005

5. Chang Y, Jung HS, Yun KE, Cho J, Cho YK, Ryu S. Cohort study of non-al-coholic fatty liver disease, NAFLD fibrosis score, and the risk of incident diabetes in a Korean population. Am J Gastroenterol (2013) 108(12):1861-8. doi:10.1038/ajg.2013.349

6. Mehran L, Amouzegar A, Rahimabad PK, Tohidi M, Tahmasebinejad Z, Azizi F. Thyroid function and metabolic syndrome: a population-based thyroid study. Horm Metab Res (2017) 49(3):192-200. doi:10.1055/s-0042-117279

7. Pucci E, Chiovato L, Pinchera A. Thyroid and lipid metabolism. Int $\mathrm{J}$ Obes Relat Metab Disord. 2000;24(2):109-12.

8. Sinha RA, Singh BK, Yen PM. Thyroid hormone regulation of hepatic lipid and carbohydrate metabolism. Trends Endocrinol Metab. 2014;25:538-5.

9. Eshraghian A, Hamidian Jahromi A. Nonalcoholic fatty liver disease and thyroid dysfunction: a systematic review. World $J$ Gastroenterol (2014) 20(25):8102-9. doi:10.3748/wjg.v20.i25.8102

10. Cable EE, Finn PD, Stebbins JW, Hou J, Ito BR, van Poelje ,PD, Linemeyer DL, Erion MD. Reduction of hepatic steatosis in rats and mice after treatment with a liver-targeted thyroid hormone receptor agonist. Hepatology 2009; 49: 407-417 [PMID: $19072834 \quad$ DOI: 10.1002/hep.22572]

11. Brenta G, Berg G, Arias P, Zago V, Schnitman M, Muzzio ,ML, Sinay I, Schreier L. Lipoprotein alterations, hepatic lipase activity, and insulin sensitivity in subclinical hypo- thyroidism: response to L-T(4) treatment. Thyroid 2007; 17:453460 [PMID: 17542675]
12. Duntas LH. Thyroid disease and lipids. Thyroid 2002; 12:287-293 [PMID: 12034052]

13. Chung GE, Kim D, Kim W, Yim JY, Park MJ, Kim YJ, Yoon ,JH, Lee HS. Nonalcoholic fatty liver disease across the spectrum of hypothyroidism. J Hepatol 2012; 57: 150-156 [PMID: 22425701 DOI: 10.1016/j.jhep.2012.02.027]

14. Hulbert AJ. Thyroid hormones and their effects: a new perspective. Biol Rev Camb Philos Soc (2000) 75(4):519-631. doi:10.1111/j.1469-185X.2000. tb00054.x

15. Grover GJ, Mellstrom K, Ye L, Malm J, Li YL, Bladh LG, et al. Selective thyroid hormone receptor-beta activation: a strategy for reduction of weight, cholesterol, and lipoprotein (a) with reduced cardiovascular liability. Proc Natl Acad Sci U S A (2003) 100(17):10067-72. doi:10.1073/pnas.1633737100

16. Erion MD, Cable EE, Ito BR, Jiang $H$, Fujitaki JM, Finn PD, et al. Targeting thyroid hormone receptor-beta agonists to the liver reduces cholesterol and triglycerides and improves the therapeutic index. Proc Natl Acad Sci U S A (2007) 104(39): 15490 doi:10.1073/pnas.0702759104

17. Gierach M, Junik R. The effect of hypothyroidism occurring in patients with metabolic syndrome. Endokrynol Pol (2015) 66(4):288-94. doi:10.5603/ EP.2015.0036

18. Silveira MG, Mendes FD, Diehl NN, Enders FT, Lindor KD. Thyroid dysfunction in primary biliary cirrhosis, primary sclerosing cholangitis and nonalcoholic fatty liver disease. Liver Int (2009) 29(7):1094-100. doi:10.1111/j.1478-3231.2009.02003.x

19. Liangpunsakul S, Chalasani N. Is hypothyroidism a risk factor for nonalcoholic steatohepatitis? J Clin 
Gastroenterol (2003) 37(4):340-3.

doi:10.1097/00004836-200310000-00014

20. Tian L, Song Y, Xing M, Zhang W, Ning $\mathrm{G}, \mathrm{Li} \mathrm{X}$, et al. A novel role for thyroidstimulating hormone: up-regulation of hepatic 3-hydroxy-3-methyl- glutarylcoenzyme A reductase expression through the cyclic adenosine monophosphate/ protein kinase $\mathrm{A} /$ cyclic adenosine monophosphate-re-sponsive element binding protein pathway. Hepatology (2010) 52(4):1401-9. doi:10.1002/hep. 23800

21. Song Y, Xu C, Shao S, Liu J, Xing W, Xu $\mathrm{J}$, et al. Thyroid-stimulating hormone regulates hepatic bile acid homeostasis via SREBP-2/HNF-4alpha/CYP7A1 axis. $J$ Hepatol (2015) 62(5):1171-9. doi:10.1016/j.jhep.2014.12.006

22. Li Y, Wang L, Zhou L, Song Y, Ma S, Yu $\mathrm{C}$, et al. Thyroid stimulating hormone increases hepatic gluconeogenesis via CRTC2. Mol Cell Endocrinol (2017) 446:70-80. doi:10.1016/j.mce.2017.02.015

23. Zhang X, Song Y, Feng M, Zhou X, Lu Y, Gao L, et al. Thyroid-stimulating hormone decreases HMG-CoA reductase phosphorylation via AMP-activated protein kinase in the liver. J Lipid Res (2015) 56(5):963-71. doi:10.1194/jlr. M047654

24. Koroglu E, Canbakan B, Atay K, Hatemi I, Tuncer M, Dobrucali A, et al. Role of oxidative stress and insulin resistance in disease severity of non-alcoholic fatty liver disease. Turk J Gastroenterol (2016) 27(4):361-6. doi:10.5152/ tjg.2016.16106

25. Bano A, Chaker L, Plompen EPC, et al. Thyroid function and the risk of nonalcoholic fatty liver disease: The Rotterdam Study. J Clin Endocrinol Metab. 2016. doi:10.1210/jc.2016-1300. 